\section{Commentary: Aortic graft infections - A potpourri of pathology without a panacea}

\author{
Evan C. Lipsitz, MD, MBA
}

In this edition of the Journal, Nissen and colleagues ${ }^{1}$ present a single-center study of patients requiring reoperation for thoracic aortic graft infections. Their results from an experienced tertiary institution are favorable in an extremely difficult patient population with a high expected morbidity and mortality. The current study includes 32 patients treated in the course of 22 years, with 19 patients having undergone ascending or arch repair and 13 patients having undergone descending or thoracoabdominal repair as the index procedure. Other reports have shown success, but there is no current accepted method for the treatment of these patients. ${ }^{2-10}$

Among the significant challenges in presenting such a population are the low occurrence rate and the heterogeneity of the group across multiple defining features. The differing complexities of ascending versus descending repair are highlighted by Nissen and colleagues. ${ }^{1}$ There are similarly complexities created when branch vessels, either in the arch or visceral and renal segments, are involved. The causative organisms and physiologic states of these patients may vary widely. In addition, the therapies for aortic pathologies evolved considerably during the study period. Four patients in the study had undergone endovascular repair as the index procedure. These patients may have presented with greater comorbidities and undergone the minimally invasive approach in an attempt to mitigate risk. The grafts used in these cases may also represent an earlier stage of technology.

The reader searching for guidance in the management of an individual patient must be able to extract the elements of the report that are most directly applicable to the case at hand. So,

\footnotetext{
From the Division of Vascular and Endovascular Surgery, Department of Cardiothoracic and Vascular Surgery, Montefiore Medical Center and the Albert Einstein College of Medicine, Bronx, NY.

Disclosures: Author receives research Support from Cook, Inc, paid directly to Montefiore Medical Center.

Received for publication Nov 18, 2019; accepted for publication Nov 19, 2019; available ahead of print Dec 9, 2019.

Address for reprints: Evan C. Lipsitz, MD, MBA, Division of Vascular and Endovascular Surgery, Department of Cardiothoracic and Vascular Surgery, Montefiore Medical Center and the Albert Einstein College of Medicine, 3400 Bainbridge Ave, MAP 4, Bronx, NY 10467 (E-mail: elipsitz@montefiore.org).

J Thorac Cardiovasc Surg 2021;162:9-10

$0022-5223 / \$ 36.00$

Copyright (C) 2019 by The American Association for Thoracic Surgery

https://doi.org/10.1016/j.jtcvs.2019.11.086
}

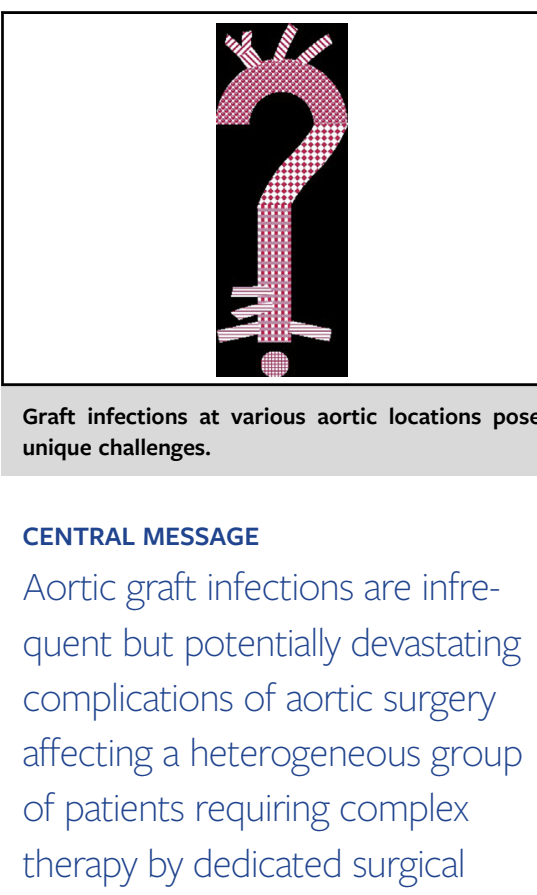

teams.

what can the reader take away from the report? First, as Nissen and colleagues ${ }^{1}$ point out, this is a complicated group of patients who are infrequently encountered, even at highvolume, tertiary centers. Many of the patients have received antibiotic therapy for some time in advance of their surgical repair, which highlights the importance of maintaining a high degree of suspicion for infection in patients with previous aortic surgery. These patients are likely to benefit from therapy at centers that have not only a robust surgical experience with aortic surgery but also a multidisciplinary team, including members from infectious disease, plastic surgery, critical care, and others. More than $50 \%$ of the patients in this series received lifelong antibiotics, and even so, there was a $25 \%$ clinically significant reinfection rate.

Nissen and colleagues ${ }^{1}$ used a case-control methodology in an attempt to eliminate the effect of a thoracic reoperation from the analysis. Although they found no statistically significant difference between the cases and controls, the numbers are small, and the survival curves demonstrate a higher 6month mortality in the group with infection. A takeaway from these curves is that if a patient survives the first 6 months after a repair of a thoracic graft infection, long-term survival should be no different than that of a patient undergoing thoracic aortic repair for progression of disease.

Patients who underwent endovascular repair (all in the descending and thoracoabdominal group) fared worse than those who underwent open repair. Nissen and colleagues ${ }^{1}$ 
point out that this group of patients likely underwent endovascular repair because of a poor physiologic state and that this alone may account for the poor results. The fact that the onset of infection, 24.8 months in the open group and 24 months in the endovascular group, did not differ suggests a similar mechanism of infection. Reducing the risk of this difficult complication is an important area of ongoing study. $^{11}$

\section{References}

1. Nissen AP, Sandhu HK, Mushtaq H, Miller CC III, Safi HJ, Estrera AL, et al. Resection and replacement of thoracic aortic graft infections. J Thorac Cardiovasc Surg. 2021;162:1-8.

2. Okita Y, Yamanaka K, Okada K. Opinion: aortic graft infection—any guidelines or just surgeon's experience lines! Semin Thorac Cardiovasc Surg. 2019;31:674-8.

3. Kahlberg A, Grandi A, Loschi D, Vermassen F, Moreels N, Chakfé N, et al. A systematic review of infected descending thoracic aortic grafts and endografts. J Vasc Surg. 2019;69:1941-51.e1.

4. Hostalrich A, Ozdemir BA, Sfeir J, Solovei L, Alric P, Canaud L. Systematic review of native and graft-related aortic infection outcome managed with orthotopic xenopericardial grafts. J Vasc Surg. 2019;69:614-8.
5. Bianco V, Kilic A, Gleason TG, Arnaoutakis GJ, Sultan I. Management of thoracic aortic graft infections. J Card Surg. 2018;33:658-65.

6. Corvera JS, Blitzer D, Copeland H, Murphy D, Hess PJ Jr, Pillai ST, et al. Repair of thoracic and thoracoabdominal mycotic aneurysms and infected aortic grafts using allograft. Ann Thorac Surg. 2018;106:1129-35.

7. Li HL, Chan YC, Cheng SW. Current evidence on management of aortic stent-graft infection: a systematic review and meta-analysis. Ann Vasc Surg. 2018;51:306-13.

8. Kreibich M, Siepe M, Morlock J, Beyersdorf F, Kondov S, Scheumann J, et al. Surgical treatment of native and prosthetic aortic infection with xenopericardial tube grafts. Ann Thorac Surg. 2018;106:498-504.

9. Masabni K, Weaver MR, Kandagatla P, Shepard AD, Huang J, Al Adas Z, et al. Cryopreserved allograft in the management of native and prosthetic aortic infections. Ann Vasc Surg. 2019;56:1-10.

10. Weiss S, Tobler EL, von Tengg-Kobligk H, Makaloski V, Becker D, Carrel TP, et al. Self made xeno-pericardial aortic tubes to treat native and aortic graft infections. Eur J Vasc Endovasc Surg. 2017;54:646-52.

11. Wilson WR, Bower TC, Creager MA, Amin-Hanjani S, O'Gara PT, Lockhart PB, et al; American Heart Association Committee on Rheumatic Fever, Endocarditis, and Kawasaki Disease of the Council on Cardiovascular Disease in the Young; Council on Cardiovascular and Stroke Nursing; Council on Cardiovascular Radiology and Intervention; Council on Cardiovascular Surgery and Anesthesia; Council on Peripheral Vascular Disease; and Stroke Council. Vascular graft infections, mycotic aneurysms, and endovascular infections: a scientific statement from the American Heart Association. Circulation. 2016;134:e412-60.
See Article page 1.

\section{Commentary: The next quarter century}

\section{Dawn S. Hui, MD, and Andrea J. Carpenter, MD, PhD}

In this edition of the Journal, Nissen and colleagues ${ }^{1}$ report on nearly a quarter century's experience with the management of thoracic aortic graft infections. Of interest is the year in which the study period ended; 2013 was the year in which the US Food and Drug Administration added acute and chronic type B aortic dissection as indications for use of the Conformable GORE TAG Thoracic Endoprosthesis (W.L. Gore and Associates, Inc, Flagstaff, Ariz). It was

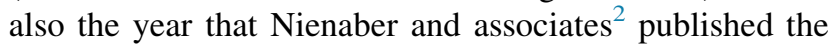
5-year results of the Investigation of Stent Grafts in Aortic Dissection with Extended Length of Follow-up (INSTEAD-

From the Department of Cardiothoracic Surgery, University of Texas Health Science Center at San Antonio, San Antonio Tex.

Disclosures: Authors have nothing to disclose with regard to commercial support.

Received for publication Nov 16, 2019; accepted for publication Nov 18, 2019; available ahead of print Dec 9, 2019.

Address for reprints: Dawn S. Hui, MD, 7703 Floyd Curl Dr, Suite 211L, San Antonio, TX 78229 (E-mail: huid@uthscsa.edu).

J Thorac Cardiovasc Surg 2021;162:10-1

$0022-5223 / \$ 36.00$

Copyright (c) 2019 by The American Association for Thoracic Surgery

https://doi.org/10.1016/j.jtcvs.2019.11.087
Check for updates

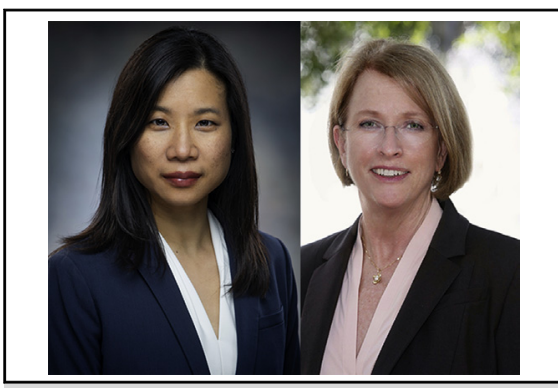

Dawn S. Hui, MD (left), and Andrea J. Carpenter, $\mathrm{MD}, \mathrm{PhD}$ (right)

CENTRAL MESSAGE

The excellent surgical results

obtained in the treatment of

thoracic aortic graft infections is

less fully realized with endografts.

This is significant in the face of

expanding TEVAR indications.

$\mathrm{XL})$ trial, showing that elective thoracic endovascular aortic repair (TEVAR) of uncomplicated type B aortic dissections had superior outcomes compared to best medical therapy alone for all-cause mortality, aorta-specific mortality, and aortic disease progression. Just a few months later, Bavaria 